\title{
A FORMAÇÃO DE PROFESSORES DA ÁREA DE CIÊNCIAS DA NATUREZA E MATEMÁTICA NA UFF ENTRE 1999 E 2009: REFLEXÕES PARA UMA OUTRA PROPOSTA
}

\section{THE TEACHERS FORMATION OF NATURAL SCIENCES AND MATHEMATICS AT UFF BETWEEN 1999 AND 2009: REFLECTIONS FOR ANOTHER PROPOSAL}

\author{
Anderson Rocha da Silva ${ }^{1}$, André Luís Gils ${ }^{2}$, Carla Wanderley de Moraes ${ }^{3}$ e Isa Costa ${ }^{4}$ \\ ${ }^{1}$ Instituto Federal de Educação, Ciência e Tecnologia do Rio de Janeiro. \\ prof_andersonrocha@yahoo.com.br \\ ${ }^{2}$ Secretaria Municipal de Educação do Rio de Janeiro, andregils@ click21.com.br \\ ${ }^{3}$ Secretaria Estadual de Educação do RJ, arlawmoraes@ gmail.com \\ ${ }^{4}$ Universidade Federal Fluminense/Departamento de Física, isac@if.uff.br
}

\section{Resumo}

O quantitativo de licenciados na área de Ciências da Natureza e Matemática vem preocupando, na última década principalmente, tanto o Ministério da Educação quanto as instituições formadoras. Reduzimos o âmbito deste trabalho à formação de licenciados em Ciências Biológicas, Física, Matemática e Química, na Universidade Federal Fluminense (UFF), durante o período de 1999 a 2009. Partimos do estudo de documentos elaborados nesta Instituição sobre cursos de graduação. Os pressupostos destes documentos são comparados com diferentes referenciais teóricos de formação de professores, para fundamentar uma análise crítica dos fluxogramas vigentes em 2009, os quais apresentam tendência de afastamento ao modelo curricular de licenciatura $3+1$ e convergir para a formação do educador-pesquisador prático-reflexivo. A análise crítica tem como fio condutor a seguinte questão: as licenciaturas científicas da UFF se aproximam das propostas curriculares atuais de formação do educador-pesquisador? Concluindo, são feitas indicações para uma futura atualização dos currículos das licenciaturas científicas, tais como: criação de um grupo de pesquisa institucional sobre formação de professores; intensificação do viés da pesquisa educacional nos componentes curriculares; atualização permanente de acordos, convênios entre a UFF e os sistemas de ensino público que propiciam parcerias; produção conjunta de trabalhos didático-pedagógico-científicos por licenciandos, professores das escolas e docentes formadores.

Palavras-chave: formação de professores; licenciaturas científicas; currículo.

\begin{abstract}
The number of graduated teachers in the Nature Science and Mathematics area has been worrying, mainly during the last decade, not only the Ministry of Education but also the forming institutions. We reduce the range of this work to the Biological Sciences, Physics, Mathematics and Chemistry teacher education at Universidade Federal Fluminense (UFF) during the period from 1999 to 2009. We start from the study of documents elaborated at this institution about undergraduate courses. The purposes of these documents are compared with different theoretical references about teacher education, in order to found a critical analysis of the current course flow charts in 2009, which present tendency of distance from the $3+1$ curriculum model and to converge toward the practical-reflexive-researcher-educator formation. The critical analysis has as conducting wire the following question: do the scientific teacher formation courses at
\end{abstract}


UFF approximate to the recent curricular proposals for the researcher-educator formation? Concluding, indications are made to a future curriculum modernization for the scientific teacher formation courses, such as: creation of an institutional research group about teacher formation; emphasis in the educational research approach in the curricular components; permanent renewal of agreements and conventions between UFF and the public education systems which propitiate partnerships; combined production of didactic-pedagogical-scientific works by undergraduate teacher formation students, school and university forming teachers.

Key words: teachers' formation; scientific teacher formation courses; curriculum.

\section{Introdução}

Há mais de uma década o quantitativo de licenciados na área de Ciências da Natureza (Biologia, Química e Física) e Matemática vem preocupando as autoridades educacionais brasileiras, tanto no âmbito do Ministério da Educação (MEC) quanto no das Instituições de Ensino Superior (IES), embora reconheçamos que tais instituições falam de lugares distintos: o MEC elaborando diretrizes de formação de professores e as IES adaptando seus currículos a estas diretrizes.

Com intuito de esboçar um quadro sobre a gravidade da situação, podemos citar dados do MEC e do Fórum de Pró-Reitores de Graduação, de 1997, sobre a evasão nas licenciaturas em Física e Química como sendo, respectivamente, de 75\% e 65\% (REHDER, 2009). Dez anos mais tarde, o Conselho Nacional de Educação (CNE) divulgou que as áreas mais carentes de professores, em escala decrescente eram: Física, Química, Matemática e Biologia, sendo que a distribuição de vagas ociosas nestes cursos apresentava os seguintes percentuais: $40 \%$, 34\%, 37\% e 30\%, respectivamente (BRASIL, 2007).

Utilizamos como ponto de partida para reflexão, o documento que estabelece as diretrizes para as graduações da Universidade Federal Fluminense (UFF, 1999), bem como o outro que dele foi consequência (UFF, 2002) e comparamos com diferentes referenciais teóricos que abordam a formação de professores (CONTRERAS, 2002; GIROUX, 1997; PERRENOUD, 2002; PIMENTA, 2008; TARDIF, 2002; TARDIF, 2000).

Nossos questionamentos principais são: em que medida as diretrizes formalizadas na UFF se aproximam dos referencias teóricos apontados? As licenciaturas estudadas apresentam currículos que se adequam às diretrizes da UFF e aos citados referenciais? Os currículos se aproximam das tendências atuais de formação docente? 
Por estas ponderações perpassa a polêmica constatada nos cenários nacional e internacional sobre a viabilidade, validade e reconhecimento da pesquisa que o professor realiza sobre sua própria prática, como professor/pesquisador (ZEICHNER, 1998; ZEICHNER; DINIZ-PEREIRA，2005; LUDKE; CRUZ，2005; VILLANI, GURIDI, 2009).

Enquanto professores de instituições de ensino superior e básico temos consciência de que a repercussão dos resultados deste trabalho no processo formativo de professores na UFF pode não ser imediata, mas consideramos oportuno o debate num momento em que, no nosso entender, medidas estão sendo tomadas pelo MEC para apagar um incêndio (falta iminente de professores de Física e Química) sem buscar os focos de origem (causas de evasão, reprovação em concursos, etc). Acreditamos que a profissão docente se encontra numa crise que é fruto das diversas perspectivas a ela atribuídas e sedimentadas pelos diferentes momentos sociais, econômicos e políticos ao longo da história. Não cremos na possibilidade de apagar, seguindo nossa metáfora, as perspectivas passadas acerca da profissão docente para erigir uma nova roupagem da mesma; acreditamos sim, que as representações anteriores são fontes de análise que podem trazer à tona aspectos sócio-históricos que irão subsidiar a compreensão da construção da especificidade do trabalho de professor, no nosso caso, das áreas científicas.

\section{As diretrizes curriculares da UFF para as licenciaturas da área de Ciências da Natureza e Matemática em comparação a alguns referenciais teóricos atuais}

Tomando-se como referencial cronológico a década de 1990, um marco fundamental para a institucionalização das discussões e elaboração de propostas para a formação de professores na UFF foi a criação da Coordenação das Licenciaturas (CL) em 1994, como órgão assessor da Pró-Reitoria de Assuntos Acadêmicos (PROAC). Em 1999, alguns de seus membros compuseram um grupo de trabalho que redigiu o documento Diretrizes para a Política de Graduação na UFF (UFF, 1999). Neste documento, no item 4.2, Diretrizes curriculares da UFF para as licenciaturasgraduação plena, foi formalizada uma postura institucional pretendida para formação docente, como ressalta o trecho:

Na UFF, a Licenciatura deve ser concebida como o curso de formação do educador-pesquisador para atuar na escola e nos espaços alternativos educacionais. Pressupõe-se que este curso proporcione uma sólida formação teórica em todas as atividades curriculares - nos conhecimentos específicos a 
Ensino, Saúde e Ambiente - V4 (3), pp. 106-118, de z. 2011

serem ensinados pela escola básica e nos conhecimentos pedagógicos - tendo a pesquisa educacional como princípio embasador. (p. 23)

Em nossa opinião, esse trecho possui um tom inovador para a época, pois rompe com a lógica da racionalidade técnica - que concebe os professores como reprodutores de um conhecimento pronto e aplicadores de metodologias de ensino normatizadas e previamente disponíveis (CONTRERAS, 2002) - e promove o professor a pesquisador educacional.

Sobre a organização curricular, o documento rompe com o modelo $3+1$ de formação, que concebe três anos para o bacharelado e um ano de disciplinas pedagógicas (UFF, 2002, p. 27), mantendo a postura de ruptura com o racionalismo técnico, pois estabelece no item 4.3 que:

A formação pedagógica precisa iniciar-se a partir dos primeiros períodos, tendo em vista que o saber docente não se constrói apenas através de complementação, sendo um processo construtivo pelo qual se dá a incorporação do pedagógico no futuro educador.

A pesquisa pedagógica se institui como componente curricular ao longo do curso, a fim de contribuir para a formação do professor crítico-reflexivo, possibilitando a atitude investigativa como condição inerente ao exercício do magistério. (p. 24)

Em outro trecho do documento, o valor da pesquisa junto à prática pedagógica é destacado e diferenciado das atividades meramente burocráticas,

Entende-se que [a formação] não se deva tornar uma prática burocrática, cumpridora apenas de normas legais. Pelo contrário, ela deve ser desenvolvida com a conotação de uma prática articulada à pesquisa, a fim de que o aluno [licenciando] vivencie as realidades educacionais. Esta prática deverá pautar-se nas vivências reflexivas críticas da gestão e da organização escolar, na dinâmica da sala de aula, na análise curricular e nos processos avaliativos. (p. 25)

Esta citação nos remete aos apontamentos feitos por Perrenoud (2002) no que tange à formação universitária: "quando se insiste nos saberes teóricos e inicia-se em metodologia de pesquisa, uma formação universitária pode tornar um profissional reflexivo 'acima da média"'(p. 103). No entanto, cabe ressaltar que este autor não qualifica o professor como pesquisador, embora defenda a construção de uma "postura reflexiva" ao longo da formação, através da criação de um habitus, conceito apropriado de Bourdieu (1972, 1980). Complementa aquele autor,

A formação de "profissionais reflexivos" deve se tornar um objetivo explicito e prioritário em um currículo de formação de professores; em vez de ser 
apenas familiarização com a futura prática, a experiência poderia, desde a formação incial, assumir a forma simultânea de uma prática "real" e "reflexiva". [...] Isso não pode ser feito por meio do micro ensino e dos estágios longos, substanciais e variados. (p. 104)

Perrenoud questiona a necessidade e suficiência da pesquisa para se formar na prática reflexiva. Depreendemos deste autor que ela é necessária, mas não suficiente. Na sua própria prática de pesquisa, ele exemplifica o que deve ser feito para propiciar o caráter reflexivo da prática docente futura: fazer interagir em parceria licenciandos e professores experientes que além de co-formadores, promoverão sua própria formação continuada na prática reflexiva.

A contraproposta de Giroux (1997) difere de Perrenoud no direcionamento da reflexividade. Enquanto o último aposta na reflexão contextualizada das vivências teóricas e práticas do caminho formativo, o primeiro aposta na reflexão pela crítica.

Para Giroux, o tratamento do professor como um intelectual o coloca em posição social de questionador, capaz de "levantar questões acerca dos princípios que subjazem os diferentes métodos didáticos, técnicas de pesquisa e teorias da educação" (p. 159). Além disso, Giroux (2002) afirma que os atuais programas de formação docente

[têm] servido para reproduzir as ideologias tecnocráticas e corporativas características das sociedades dominantes [...] concebidos para criar intelectuais que operam a serviço de interesses do Estado, e cuja função social é primordialmente manter e legitimar o status quo (p. 128).

Por isso, o autor defende que essa formação não deve desconsiderar as diferentes culturas nas quais estão imersos professores e alunos, além de suas histórias pessoais; entende que pedagogia e cultura devem interagir para a formação de intelectuais críticos.

Em uma outra concepção, Tardif (2002) considera o professor como ator racional, que para lidar com a incerteza e a imprevisão em sala de aula, precisa que sua formação priorize a prática na escola enquanto lugar de trabalho dos professores. Dessa forma, sugere que os saberes transmitidos pelas instituições formadoras devam ser concebidos e adquiridos em estreita relação com as escolas.

Entre 1999 e 2002, a CL aprofundou estudos e elaborou um texto com fundamentação teórica mais consistente e ampliada, específica para as licenciaturas: as Diretrizes para formação de professores na UFF (UFF, 2002). Muitas dessas orientações são reelaborações das encontradas no item 4.2. Diretrizes curriculares da 
UFF para as licenciaturas-graduação plena do documento de 99. Em um dos itens dessas diretrizes, formaliza a prática e o estágio curricular supervisionado, orientando que estes "devem ser desenvolvidos com a conotação de uma prática e um estágio articulados à pesquisa" (p. 17 e 18).

Estes pressupostos ratificam um perfil de profissional docente pesquisador já apontado no documento de 99, que coloca a pesquisa associada ao exercício crítico, reflexivo e investigativo das realidades educacionais como instâncias a serem priorizadas no processo formativo.

Sobre o estágio supervisionado, cabe aqui ressaltarmos dois outros fatos que marcaram o trabalho da CL, após a publicação das Diretrizes (UFF, 2002): o primeiro, em agosto de 2002, foi o estabelecimento por cinco anos de um convênio com a Secretaria Estadual de Educação do RJ, a fim de institucionalizar e oficializar a realização das atividades de licenciandos da UFF em escolas da rede estadual; formalização que manifesta a influência tardifiana pois prioriza a parceria universidadeescola. $\mathrm{O}$ segundo, acreditamos que tenha sido pioneiro no cenário nacional da época, foi a criação, em 2003, da Subcoordenadoria de Apoio à Prática Pedagógica Discente (SAPPD), como órgão assessor da PROAC para gerenciar a política de relações entre a UFF e o sistema de ensino da Educação Básica. A SAPPD está instalada no mesmo campus que a Faculdade de Educação, pois sua coordenação é feita por docentes desta unidade de ensino. Esta foi a concretização de uma meta da CL para garantir campos de estágio e proporcionar vivências pedagógicas a licenciandos participantes em Projetos de Ensino, bem como gerenciar a distribuição da bolsa de licenciatura, ou de iniciação à docência, provida com recursos internos da UFF.

No entanto, nosso ponto de vista é que a Universidade deve atentar para as medidas propostas recentemente pelo MEC, como: a formação "aligeirada", implantada pelo Sistema Nacional Público de Formação de Professores (SNPFP); o "desvinculamento do bacharelado da licenciatura" (p. 24), pela possibilidade, na oferta de componentes curriculares diferenciados para cada titulação, ferir a “indissociabilidade entre ensino, pesquisa e extensão" (p. 24), de maneira a não comprometer a qualidade da formação do licenciando.

Além disso, destacamos outros desafios para a reestruturação das licenciaturas citados no documento de 2002, como: "elaborar uma política de formação de formadores" e "manter permanente interação entre os bacharelados e licenciaturas em cada área do conhecimento" (UFF, 2002, p. 25). Nos dois desafios citados a situação se 
torna complexa nas licenciaturas da área das Ciências da Natureza e Matemática. Primeiramente, pelo mito naturalizado por vários formadores, que em geral são pesquisadores de áreas desvinculadas à Educação, de que basta conhecer/saber um assunto para ensiná-lo bem, com aprendizagem garantida; dessa maneira, esses formadores não são receptivos a programas ou atividades de formação, ranços da racionalidade técnica subjacente ao modelo de formação 3+1, no qual, esses professores foram formados, já que essa característica da formação docente vem desde as primeiras experiências de licenciatura no Brasil (na década de 1930) e prevalece até hoje (MONTEIRO, 2005; AYRES, 2005).

Isto nos leva ao segundo ponto, em que se exacerba nas licenciaturas científicas, por parte de alguns formadores, uma discriminação dos licenciandos movida pela ideologia de que os professores do ensino básico são reprodutores de conhecimentos desenvolvidos na Universidade pelos bacharéis, subalternizando a atividade docente e vinculando-a a algo menor, dissociado de pesquisa e reflexão.

Neste sentido, concordamos com Shulman (1986), em que a valorização dos conhecimentos de conteúdo, pedagógicos e curriculares, de maneira nenhuma deve apontar somente para a especificidade dos conhecimentos cientificizados, próprios da profissão de professor, mas deve, tal como aconselha Domite (2004), permitir incorporar também os saberes dos alunos ao processo de formação, contribuindo para que esta se dê numa via de mão dupla: legitimando também os conhecimentos dos alunos junto aos dos professores.

Pelo estudo dos referenciais teóricos citados, constatamos a importância do viés da pesquisa na formação e na prática docente como questão essencial para que tanto o futuro profissional, quanto aquele em exercício seja um educador reflexivo.

Diante da discussão realizada sobre as diretrizes curriculares para licenciatura da UFF frente os referenciais supracitados, cabe agora analisarmos os fluxogramas dos cursos para avaliarmos em que medida essas diretrizes foram corporificadas na estrutura curricular.

\section{Os fluxogramas curriculares das licenciaturas da UFF na área de Ciências da Natureza e Matemática frente às diretrizes curriculares}

A partir dos fluxogramas curriculares das Licenciaturas da área de Ciências da Natureza e Matemática da UFF uma análise é feita junto às diretrizes já discutidas e 
frente ao escopo de referenciais teóricos apresentados, avaliamos em que medida esses documentos se aproximaram e sedimentamos algumas observações:

- Fogem do modelo $3+1$, no entanto, constatamos que as licenciaturas em Ciências Biológicas e Matemática seguem um modelo 2+2, desta forma qualificado em analogia ao $3+1$;

- Apresentam componentes curriculares chamados de integradores, servindo de ponte entre os conteúdos específicos e pedagógicos, propiciando a construção do que Shulman $(1987$, p. 8) denomina de conhecimento pedagógico do conteúdo (pedagogical content knowledge);

- Nenhum dos currículos cumpre, até março de 2010, totalmente as Diretrizes Nacionais do MEC de 400 H de Estágio Supervisionado, 400 H de Práticas Pedagógicas e o curso de Linguagem Brasileira de Sinais (LIBRAS), como disciplina obrigatória.

- $\quad$ Somente os de Física e Química seguem a diretriz nacional de que os conteúdos pedagógicos devem permear a estrutura curricular da licenciatura desde os primeiros períodos;

- $\quad$ Somente o curso de Ciências Biológicas não oferece a disciplina "História das Ciências", obrigatória segundo orientação das Diretrizes;

- As licenciaturas noturnas em Física e Química apresentam os mesmos componentes curriculares que são ministrados nos cursos diurnos, mas com duração estendida ( 3 períodos a mais) para garantir a mesma qualidade da formação.

A Tabela 1 resume outras características da estrutura curricular das licenciaturas científicas da UFF a partir de seus fluxogramas.

Tabela 1: Características da estrutura curricular das licenciaturas científicas da UFF, a partir da análise de seus fluxogramas

\begin{tabular}{|c|c|c|c|c|}
\hline \multirow{2}{*}{$\begin{array}{c}\text { Característica } \\
\text { extraída do } \\
\text { fluxograma }\end{array}$} & \multicolumn{3}{|c|}{ Curso de Licenciatura da UFF } \\
\cline { 2 - 5 } & $\begin{array}{c}\text { Ciências } \\
\text { Biológicas }\end{array}$ & Física & Matemática & Química \\
\hline
\end{tabular}




\begin{tabular}{|c|c|c|c|c|}
\hline $\begin{array}{l}\text { Componentes } \\
\text { Curriculares } \\
\text { Integradores }\end{array}$ & $\begin{array}{l}\text { Instrumentação } \\
\text { em Educação } \\
\text { Ambiental; } \\
\text { Instrumentação } \\
\text { em Ensino de } \\
\text { Biologia; } \\
\text { Instrumentação } \\
\text { para a Prática de } \\
\text { Ensino; } \\
\text { Iniciação à } \\
\text { Docência I a IV. }\end{array}$ & $\begin{array}{l}\text { Produção de } \\
\text { Material } \\
\text { Didático e } \\
\text { Estratégias } \\
\text { para o } \\
\text { Ensino de } \\
\text { Física I e II; } \\
\text { Atividades } \\
\text { Acadêmicas } \\
\text { Curriculares. }\end{array}$ & $\begin{array}{l}\text { Educação } \\
\text { Matemática- } \\
\text { Análise e } \\
\text { Álgebra; } \\
\text { Educação } \\
\text { Matemática- } \\
\text { Geometria. }\end{array}$ & $\begin{array}{l}\text { Tutoria I a } \\
\text { III; } \\
\text { Metodologia } \\
\text { e } \\
\text { Instrumenta } \\
\text { ção para o } \\
\text { Ensino de } \\
\text { Química I e } \\
\text { II; Iniciação } \\
\text { à Docência ; } \\
\text { Atividades } \\
\text { Acadêmicas } \\
\text { Curriculares. }\end{array}$ \\
\hline $\begin{array}{l}\text { Componentes } \\
\text { Curriculares } \\
\text { Obrigatórios } \\
\text { Inovadores }\end{array}$ & $\begin{array}{l}\text { Iniciação à } \\
\text { Docência; } \\
\text { Redação } \\
\text { Científica; } \\
\text { Bioética; } \\
\text { Instrumentação } \\
\text { em Educação } \\
\text { Ambiental. }\end{array}$ & $\begin{array}{l}\text { Produção de } \\
\text { Material } \\
\text { Didático e } \\
\text { Estratégias } \\
\text { para o } \\
\text { Ensino de } \\
\text { Física; } \\
\text { Atividades } \\
\text { Acadêmicas } \\
\text { Curriculares. }\end{array}$ & $\begin{array}{l}\text { Educação } \\
\text { Matemática. }\end{array}$ & $\begin{array}{l}\text { Tutoria; } \\
\text { Iniciação à } \\
\text { Docência; } \\
\text { Atividades } \\
\text { Acadêmicas } \\
\text { Curriculares; } \\
\text { Introdução à } \\
\text { Química } \\
\text { Ambiental. }\end{array}$ \\
\hline $\begin{array}{l}\text { Exigência de Trabalho } \\
\text { de Conclusão de Curso }\end{array}$ & Sim & Não & Não & Sim \\
\hline $\begin{array}{l}\text { Vinculação da } \\
\text { Pesquisa à Prática de } \\
\text { Ensino }\end{array}$ & Sim & Não & Não & Sim \\
\hline
\end{tabular}

Cabe aqui um questionamento: diante de todo o detalhamento dos currículos das licenciaturas científicas da UFF, os cursos mostram indícios de que potencializam a formação de educadores-pesquisadores? Tomando como critério que seriam aqueles cursos que apresentassem componentes curriculares que estão explicitamente ligados aos temas que envolvem atividade de pesquisa, como: Pesquisa e Prática de Ensino, Redação Científica e Tutorias, concluímos que são os cursos de Ciências Biológicas e Química. No entanto, a licenciatura em Física é a que mais tem reformulado o currículo, sempre procurando atender as tendências das pesquisas em formação de professores desde 1991. O curso de Ciências Biológicas já foi criado dentro dos moldes das Diretrizes para Formação de Professores do MEC, e isto faz uma diferença. Já os cursos de Matemática e Química sofreram um número bem reduzido de mudanças curriculares.

\section{Indicações para uma nova proposta de Diretrizes}


Na elaboração de novas diretrizes de formação de professores na UFF, há que se atentar para as divergências e inconsistências constatadas na Tabela 1, principalmente no que diz respeito às exigências nacionais. Para que essas diretrizes atendam às especificidades das licenciaturas científicas, sugerimos a criação de um grupo de pesquisa interlicenciaturas na UFF, para se dedicar ao estudo dessas mesmas particularidades e que tenha inscrição no Grupo Temático 08 (GT 08) da Associação Nacional de Pós-Graduação em Educação (ANPED).

Como desdobramento de estudos/pesquisas/propostas desse eventual grupo de pesquisa temos a expectativa de que surjam iniciativas de promoção da intertransdisciplinaridade na formação inicial; por exemplo, com o tratamento de temas transversais (Meio Ambiente, Ciência/Tecnologia/Sociedade, etc).

Propomos também que seja intensificado o viés da pesquisa educacional (levantamentos quantitativos e qualitativos, entrevistas, observação e estudo da realidade concreta, etc) nas disciplinas/atividades integradoras e nas Práticas de Ensino, com a discussão de bibliografia relativa ao ensino não só de cada ciência em si, mas também de trabalhos multi, inter e transdisciplinares.

Para garantir a continuidade de políticas públicas desvinculadas de políticas governamentais, é importante que se mantenham atualizados acordos, convênios, ou qualquer outro tipo de compromisso entre a UFF e os sistemas de ensino público, o que oficializa e viabiliza a interação/parceria entre a universidade e as escolas públicas.

Finalmente, julgamos que o exercício da produção conjunta (licenciandos/professores da escola/docentes da universidade) de trabalhos didáticopedagógico-científicos, com a finalidade de sua divulgação em eventos de ensino das

Ciências, contribuirá para uma sedimentação e reconhecimento da pesquisa do professor.

\section{Considerações finais}

Ao longo deste trabalho, mencionamos alguns referenciais relevantes que abordam a formação docente e refletimos sobre os documentos institucionais que a UFF produziu sobre a Licenciatura (UFF, 1999 e 2002) para que pudéssemos com mais propriedade comparar os fluxogramas curriculares mais próximos das diretrizes formalizadas, bem como perceber os cursos que esboçam em sua estrutura a formação do professor pesquisador e reflexivo, viés contrário à racionalidade técnica. 
Nos fluxogramas analisados, observamos que há interesse na formação de um professor que paute suas ações em sala de aula e no exercício da reflexão e da pesquisa, proposta que rompe com o modelo $3+1$, pois percebemos a presença de disciplinas de formação pedagógica ao longo do curso, medida que fortalece o caráter investigadorcrítico-reflexivo do licenciando e não centradas no último ano como complemento à formação específica de cada área. A análise realizada foi de caráter documental, podendo ser considerada até certo ponto superficial. Um estudo mais rigoroso exigiria uma avaliação pormenorizada das ementas e objetivos de cada disciplina citada, bem como um contato com docentes que as ministram, o que extrapola os objetivos deste trabalho.

Além disso, há a necessidade de se implantar uma política de formação de formadores de professores com maior integração entre licenciaturas e bacharelados; para isso, reconhecemos a necessidade de superar alguns entraves históricos acerca da profissão docente, como a subalternização das licenciaturas frente aos bacharelados.

De acordo com os referenciais teóricos apresentados, acreditamos em uma formação docente que oportunize a prática em sala de aula e valorize as vivências reflexivas advindas desta prática durante a graduação, não no sentido de desconsiderar contribuições teóricas para a formação, nem do licenciando aprender na prática e sim com a prática subsidiada pela troca de experiências e saberes entre professores universitários, licenciandos e os da escola, para que na vivência do ambiente do trabalho docente este perceba a complexidade das interações estabelecidas ali e seja estimulado a refletir sobre os conteúdos teóricos e pesquisar este ambiente. Sendo assim, repudiamos também as reformas e currículos pautados na desvalorização dessa formação teórica aligeirando-a, improvisando-a ou adequando-a a interesses sociais e econômicos que legitimam e mantêm o status quo.

Essa convivência entre escola e universidade, bem como as parcerias que se estabelecem entre todos os protagonistas do processo formativo: docentes da universidade, professores da escola e licenciando e alunos, pode permitir uma formação mais sólida, pois o licenciando estará também reconhecendo a sua profissão não como solitária ou individual, como preconizado nas políticas neoliberais, mas coletiva. E isso é bastante relevante para que ele comece a se conscientizar de como sua profissão vem sendo considerada no interior das políticas públicas e das pesquisas de formação, incluindo as analisadas neste trabalho. Sendo assim, objetivamos, uma formação que 
possa incorporar tanto os anseios e desejos da sociedade, para sua melhoria, como os saberes daqueles que a realizam.

\section{REFERÊNCIAS}

AYRES, Ana Cléa Braga Moreira. As tensões entre a licenciatura e o bacharelado: a formação dos professores de Biologia como territórios contestados. In: MARANDINO, M.; SELlES, S. E.; FERREIRA, M. S. \& AMORIM, A. C. R. (Orgs.). Ensino de Biologia: conhecimentos e valores em disputa. Niterói: EdUFF, 2005, p. 182-197.

BOURDIEU, Pierre. The Logic of Practice. Cambridge: Polity Press, 1980. . Esboço de uma teoria da prática. Precedido de três estudos de etnologia Kabila. Oeiras: Celta, 1972.

BRASIL. MEC/CNE. Escassez de professores no ensino médio: propostas estruturais e emergenciais. Brasília: CNE, 2007.

CONTRERAS, José. Autonomia de Professores. São Paulo: Cortez, 2002.

DOMITE, M. C. S. Da compreensão sobre formação de professores e professoras numa perspectiva etnomatemática. In: KNIJNIK,G., WANDERER, F. , OLIVEIRA, C.J. (orgs.). Etnomatemática: currículo e formação de professores. Santa Cruz do Sul: EDUNISC, 2004.

GIROUX, Henry A. Os Professores como Intelectuais: rumo a uma pedagogia crítica da aprendizagem. Porto Alegre: Artes Médicas, 1997.

GIROUX, Henry A.; McLAREN, Peter. Formação do Professor como uma contraesfera pública: a Pedagogia Radical como uma forma de política cultural. In: MOREIRA, Antonio Flavio Barbosa; SILVA, Tomaz Tadeu da (orgs.). Currículo, cultura e sociedade. São Paulo: Cortez, 2002, p. 125-151.

LÜDKE, Menga; CRUZ, Giseli Barreto da. Aproximando universidade e escola de educação básica pela pesquisa. Cadernos de Pesquisa, v. 35, n. 125, maio 2005. Disponível em: http://www.scielo.br/scielo.php?scrip=sci_arttext\&pid=S010015742005000200006\&nrm=iso. Acesso em 15/07/2009.

MONTEIRO, Ana Maria. Formação docente: território contestado. In: MARANDINO, Marta, SELLES, Sandra, FERREIRA, Márcia Serra e AMORIM, Antonio Carlos. (orgs). Ensino de Biologia: conhecimentos e valores em disputa Niterói: EdUFF, 2005, p. 153-170.

PERRENOUD, Philippe. A Prática Reflexiva no Ofício do Professor: profissionalização e razão pedagógica. Porto Alegre: Artmed Editora, 2002.

PIMENTA, Selma Garrido. Professor Reflexivo: construindo uma crítica. In: PIMENTA, Selma Garrido; GHEDIN, Evandro (orgs.). Professor Reflexivo no Brasil: gênese e crítica de um conceito, 5. ed., São Paulo: Cortez, 2008, p. 17.

REHDER, Maria. Faltam 246 Mil Docentes no Nível Médio. O Estado de S. Paulo, 28/01/2009. Disponível em: http://www.thekey.com.br/napp/aempresa/boletimthekeymostra.asp?id_boletim=80.

Acesso em: 20/02/2010.

SHULMAN, Lee. Knowledge and Teaching: foundations of the new reform. Harvard Educational Review, v. 57, n. 1, p.1-22, 1987.

Those Who Understand: knowledge growth in teaching. Harvard Educational Review, v. 15, n. 2, p. 4-14, 1986. 
TARDIF, Maurice. As concepções do saber dos professores de acordo com diferentes tradições teóricas e intelectuais. Mimeo., 2000.

TARDIF, Maurice. Saberes docentes e formação profissional. 8. ed. Petrópolis, RJ: Vozes, 2002.

UFF. Diretrizes para a formação de professores na UFF/coordenação das licenciaturas da UFF. Niterói: EdUFF, 2002.

. Diretrizes para a Política de Graduação na UFF/Fórum de coordenadores para os Cursos de Graduação. Niterói: EdUFF, setembro 1999.

VILLANI, Alberto; GURIDI, Verônica. Profesor Investigador y Formación de Profesores. Tecné, Episteme y Didaxis: TE $\Delta$ No. Extraordinario, 2009. Disponível em: http://www.pedagogica.edu.co/revistas/ojs/index.php/TED/article/view/248/239. Acesso em: 20/03/2010.

ZEICHNER, Kenneth M.; DINIZ-PEREIRA, Júlio Emílio. Pesquisa dos educadores e formação docente voltada para a transformação social. Cadernos de Pesquisa, vol.35, n. 125, maio 2005. Disponível em: http://www.scielo.br/pdf/cp/v35n125/a0535125.pdf. Acesso em 20/07/2009.

ZEICHNER, Kenneth M. Para além da divisão entre professor-pesquisador e pesquisador acadêmico. In: GERALDI, Corinta M.; FIORENTINI, Dario; PEREIRA, Elisabete, M. (orgs.). Cartografia do trabalho docente: professor(a)-pesquisador(a). Campinas: Mercado de Letras; ABL, 1998, p. 207-236. 